\title{
Ten-Year Monitoring of the Grandes Jorasses Glaciers Kinematics. Limits, Potentialities, and Possible Applications of Different Monitoring Systems
}

\author{
Niccolò Dematteis ${ }^{1}{ }^{\mathbb{D}}$, Daniele Giordan ${ }^{1, * \mathbb{C}}$, Fabrizio Troilo ${ }^{2} \mathbb{D}$, Aleksandra Wrzesniak ${ }^{1}$ and Danilo Godone ${ }^{1} \mathbb{C}$ \\ 1 Italian National Research Council, Research Institute for Geo-Hydrological Protection (CNR-IRPI), \\ Strada delle Cacce 73, 10135 Torino, Italy; niccolo.dematteis@irpi.cnr.it (N.D.); \\ aleksandra.wrzesniak@irpi.cnr.it (A.W.); danilo.godone@irpi.cnr.it (D.G.) \\ 2 Fondazione Montagna Sicura, Località Villard de la Palud, 1, 11013 Courmayeur, Italy; ftroilo@fondms.org \\ * Correspondence: daniele.giordan@irpi.cnr.it
}

Citation: Dematteis, N.; Giordan, D.; Troilo, F.; Wrzesniak, A.; Godone, D. Ten-Year Monitoring of the Grandes Jorasses Glaciers Kinematics. Limits, Potentialities, and Possible

Applications of Different Monitoring Systems. Remote Sens. 2021, 13, 3005. https://doi.org/10.3390/rs13153005

Academic Editors: Davide Fugazza Roberto Sergio Azzoni,

Antonella Senese and

Giovanni Baccolo

Received: 16 June 2021

Accepted: 22 July 2021

Published: 30 July 2021

Publisher's Note: MDPI stays neutral with regard to jurisdictional claims in published maps and institutional affiliations.

Copyright: (c) 2021 by the authors. Licensee MDPI, Basel, Switzerland. This article is an open access article distributed under the terms and conditions of the Creative Commons Attribution (CC BY) license (https:/ creativecommons.org/licenses/by/ $4.0 /)$

\begin{abstract}
In the Ferret Valley (NW Italy), anthropic activities coexist close to the Grandes Jorasses massif's glaciological complex. In the past, break-off events have caused damage to people and infrastructure. These events concerned two specific sectors: the Montitaz Lobe (Planpincieux Glacier) and the Whymper Serac (Grandes Jorasses Glacier). Since 2010, permanent and discontinuous survey campaigns have been conducted to identify potential failure precursors, investigate the glacier instability processes, and explore different monitoring approaches. Most of the existing terrestrial apparatuses that measure the surface kinematics have been adopted in the Grandes Jorasses area. The monitoring sites in this specific area are characterized by severe weather, complex geometry, logistic difficulties, and rapid processes dynamics. Such exceptional conditions highlighted the limitations and potentialities of the adopted monitoring approaches, including robotic total station (RTS), GNSS receivers, digital image correlation applied to time-lapse imagery, and terrestrial radar interferometry (TRI). We examined the measurement uncertainty of each system and their monitoring performances. We discussed their principal limitations and possible use for warning purposes. In the Grandes Jorasses area, the use of a time-lapse camera appeared to be a versatile and cost-effective solution, which, however is not suitable for warning applications, as it does not guarantee data continuity. RTS and GNSS have warning potentialities, but the target installation and maintenance in remote environments remain challenging. TRI is the most effective monitoring system for early warning purposes in such harsh conditions, as it provides near-real-time measurements. However, radar equipment is very costly and requires extreme logistic effort. In this framework, we present data integration strategies to overcome the abovementioned limits and we demonstrate that these strategies are optimal solutions to obtain data continuity and robustness.
\end{abstract}

Keywords: glaciers; monitoring; natural hazards; data integration; glacier flow

\section{Introduction}

Mountain glaciers are a crucial element for the local economy in terms of freshwater supply, hydroelectric production, and tourist activities [1]. Glacier surface mass balance, elevation change, and terminus retreat are often quantitatively surveyed to evaluate their current state and recent evolution [2]. However, such monitoring activities are usually conducted periodically (e.g., with seasonal or annual revisit time) due to the investigated processes' relatively slow dynamics.

Conversely, glacial phenomena such as ice avalanches and glacier lake outburst floods develop and evolve more rapidly, with a time scale from days to minutes. They represent a potential risk for infrastructure and the population [3-5]. Therefore, high temporal frequency monitoring is necessary to observe such rapid processes and acquire a detailed sequence of physical parameters that allows correct data analysis. Thereby, it is possible to 
provide insight into the investigated phenomena and support decision-makers in managing glacial risk.

The majority of efforts dedicated to technological development have focused on new technologies and methodologies to measure surface displacement, as the surface kinematic is the most connected variable to potential failures. Spaceborne surveys cover wide areas, providing data without great human effort and the recent Sentinel program has notably reduced the revisit time. Nevertheless, their frequency is not yet sufficient to observe rapid processes and complex geometries typical of mountain glaciers, hampering the spaceborne measurement.

Only terrestrial systems can provide a sufficiently temporally dense dataset. However, they have the disadvantage of observing relatively small areas and requiring significant human and financial input. Glaciers are usually located in remote and challenging environments and the existing commercial instrumentations were not designed for glaciological surveys specifically. Therefore, continuous glaciological long-term monitoring campaigns are not common.

According to Watson and Quincey [6], terrestrial measurement techniques of glacier movement include total station/theodolites, GNSS receivers (hereafter GNSS) and timelapse cameras (TLC) using the digital image correlation (DIC) method. Additionally, terrestrial radar interferometry (TRI) proved to be a valuable tool in this regard [7].

Theodolites for surveying glacier flow have been used in the past century [8,9]. Typically, a series of stacks or stones were periodically measured and replaced in their original positions. Recently, the adoption of robotic total station (RTS) allowed us to obtain longterm continuous surveys of glaciers $[10,11]$. The RTS combines an electronic theodolite and a laser range finder to measure the three-dimensional position of a given target with millimetric sensitivity. The RTS autonomously acquires during day and night, but dense fog or clouds hamper its performance. The RTS system requires the installation of reflective prisms within the monitored area, while prisms placed in stable areas are used to reduce the atmospheric artefacts on the measurements and determine angular offsets. A network of passive targets entails the necessity of periodic maintenance, which can be complicated in challenging areas.

GNSS measure their own three-dimensional position with centimeter to millimeter precision. They are composed of an antenna and an L-band microwave receiver. More sophisticated GNSS acquire multiple frequencies to filter the ionospheric and atmospheric influence better. Currently, the use of geodetic sensors is common in glaciology [12-15] due to their light portability and simple use. However, most of the applications concern discontinuous manual surveys, involving human access into the glacierized area. Permanent GNSS networks are less frequent because they need periodic maintenance and a continuous on-site power supply. Examples can be found in [10,16,17].

One of the first applications of terrestrial DIC to glacier motion was described by Evans [18], who used digitalized image negatives of the Godley Glacier (New Zealand). Subsequently, terrestrial DIC has been adopted in a number of glaciological studies [19-22]. Typically, DIC is applied to time-lapse cameras deployed on stable ground/surfaces to minimize image misregistration. The principle of DIC is to search for the position of a given patch between two images. Thereby, DIC detects the spatially distributed displacement components orthogonal to the line of sight (LOS). The pixel's footprint is typically of the order of centimeters and depends on camera specifications and camera-to-target distance. In optimal contexts, DIC can provide sub-pixel measurements. However, reliable results are more frequent for displacement larger than a few pixels. The major limitation of DIC is the need for favorable visibility and illumination conditions. This often requires the manual selection of the images to be processed in order to discard the corrupted ones [23]. For these reasons, the temporal frequency of the results is often on a daily basis.

The first TRI surveys of a glacier were conducted experimentally in the Belvedere Glacier (Italy) [7,24] and Gorner Glacier (Switzerland) [25]. The authors adopted prototypes of two interferometric apparatuses (i) ground-based synthetic aperture radar (GBSAR) 
and (ii) real aperture radar (RAR), respectively. The GBSAR is the commonest TRI system. It is composed of small transmitting and receiver antennas that slide onto a linear rail, typically 2-3 m long. This movement has a twofold effect: first, it allows us to obtain an aerial distribution of the surveyed displacement, and second, it simulates a wider antenna to obtain a finer spatial resolution. Differently, a RAR system uses large antennas that rotate about a vertical axis to scan the whole scene. The increased antenna dimension entails a better signal-to-noise ratio (SNR), which permits a longer operational range (up to $10-15 \mathrm{~km}$ ), but the financial cost is usually higher than the GBSAR. Subsequently, TRI has occasionally been adopted in short-term surveying campaigns [26-28]. TRI measures the phase difference between two electromagnetic pulses, which is directly linked to the target displacement parallel to the LOS. Usually, terrestrial radars operate in Ku-band, which corresponds approximately to a wavelength of $\lambda=15-20 \mathrm{~mm}$. Therefore, the TRI measurement sensitivity is submillimeter. However, the maximum displacement detected between two acquisitions is $\lambda / 2<10 \mathrm{~mm}$ [29]. Typical acquisition frequencies vary from seconds to minutes. TRI surveys can be conducted continuously during day and night and in all meteorological conditions. Nevertheless, atmospheric changes affect the measurement [30]. In glacial environments, severe weather frequently occurs [31]. Specific methods must be adopted to filter the atmospheric influence properly [31-33]. TRI systems require a considerable power supply and logistic efforts. Therefore, long-term surveys are difficult to conduct in remote environments, like that of the Mont Eiger (Switzerland) [32].

Typically, the scope of terrestrial glaciological campaigns focuses on the investigation of glacial processes, but the metrological effectiveness of survey sensors and techniques has seldom been analyzed in recent years $[6,33,34]$.

In this paper, we present applications and results of the abovementioned monitoring techniques that have been adopted in the glacial complex of the Grandes Jorasses (Italy) during the last decade. We conducted various campaigns using RTS, GNSS, DIC and TRI. These surveys had multiple objectives. Since the Grandes Jorasses is an area where glacial hazards are frequent and can menace the population, the first objective was the glacier monitoring for potential failure precursor identification [35] and for glacial risk evaluation [36]. The second objective was the glacier behavior investigation to enhance our understanding of the instability processes [37]. The third objective was to explore existing and innovative approaches for effective continuous glacier monitoring [23,38-41]. The presented work focuses of the latter topic.

More than 10 years of monitoring in a high-mountain glacial environment with exceptional characteristics of meteorology, geometry, and process dynamics allowed for the exploration of the effectiveness, limits, and potentialities of various surveying methods. In this paper, we present these limits and potentialities in a comprehensive view, and we discuss the use of RTS, GNSS, DIC, and TRI for glacier observation, investigation, and glacial hazard warning.

Section 2 presents the study area of the Grandes Jorasses glacial complex, while Section 3 provides the technical specification of the survey systems and describes their operative applications, including the strategies adopted to take advantage of their measurement capability. Section 4 pertains to the description of the kind of data that can be provided by the various systems and briefly presents the related uncertainties. Sections 5 and 6 discuss the findings of more than 10 years of glacial monitoring.

\section{Area of Interest: The Grandes Jorasses Glacial Complex}

The Planpincieux Glacier (WGI \# IT4L01517018) and Grandes Jorasses Glacier (WGI \#IT4L01517019) [42] are located in Ferret Valley on the Italian side of the Grandes Jorasses massif (Figure 1). These two glaciers form a unique glacial complex (GLIMS ID G006977E45859N) [43] extended between $2600 \mathrm{~m}$ a.s.l. and $4206 \mathrm{~m}$ a.s.l. with a mean South-East aspect. 

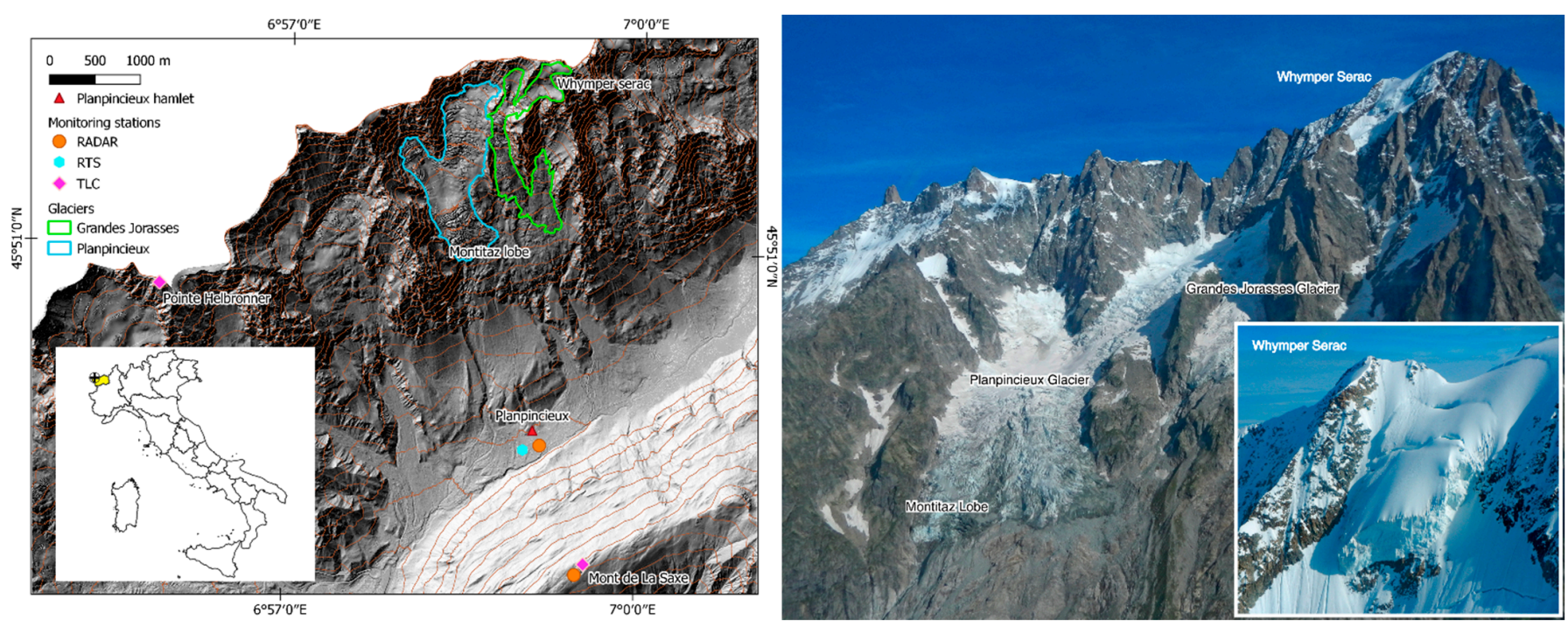

Figure 1. Left panel: overview of the study area. Right panel: Planpincieux and Grandes Jorasses glaciers. In the white box, a closer perspective of the Whymper Serac is shown.

The total glacierised surface of the glacial complex is $1.594 \mathrm{~km}^{2}$ divided into $1.008 \mathrm{~km}^{2}$ for the Planpincieux Glacier and $0.586 \mathrm{~km}^{2}$ for the Grandes Jorasses Glacier (Regional glacier inventory of Aosta Valley, update 2019). The Ferret Valley is a renowned tourist locality in the Mont Blanc area and it is a clear example of the relationship between glaciers and human infrastructure. As is common in the Alpine region, the anthropic pressure in this area has progressively augmented in the last fifty years. The vulnerability of the infrastructure in the valley currently represents a critical factor that requires the correct management of glacial hazards. Frequent and recurrent break-off events from the Montitaz Lobe (ML) of the Planpincieux Glacier and the Whymper Serac (WS) of the Grandes Jorasses Glacier cause damage to the underlying Planpincieux hamlet [36,37]. Major survey efforts have been dedicated to monitoring these two glacial sectors.

The ablation area of the Planpincieux Glacier is composed of two lobes. The ML (Figure 1) is a $32^{\circ}$-steep icefall whose terminus lies at $2600 \mathrm{~m}$ a.s.l. and ends in correspondence with a bedrock cliff that induces frequent calving [37].

The WS is located in the upper part of the Grandes Jorasses Glacier (Figure 1), at approximately $4000 \mathrm{~m}$ a.s.l. Six boreholes drilled in January 1998 showed basal temperatures below $0^{\circ}$ [44]. Recent observations indicate that the basal temperature has risen (Vincent, 2020, personal communication). The serac is $45^{\circ}$-steep and it is classified as an unbalanced hanging glacier [44]. The WS follows an evolution cycle characterized by its progressive volume increase until its shape and mass reach unstable conditions, and consequently, it collapses [35,44,45]. The last break-offs occurred in August 1993 (causing the fatality of eight mountaineers), in June 1998 [36], in September 2014 [35] and during the Autumn of 2020.

\section{Implementation: Survey Methods}

In the last decade, the surveys in the Grandes Jorasses area were conducted by various technologies and techniques [41]. Since one goal was to monitor the glacier kinematics to detect potential hazards, particular attention was dedicated to systems that survey the surface displacement. In the following, we present these systems and briefly describe the procedures of monitoring system management. In Table 1, we report the details of the survey campaigns conducted in the Grandes Jorasses area. 
Table 1. Survey campaigns in the Grandes Jorasses glacial complex since 2010 (TLC = time-lapse camera; GNSS = global navigation satellite system; RTS = robotic total station; TRI = terrestrial radar interferometry).

\begin{tabular}{|c|c|c|c|c|}
\hline Apparatus & Monitored Area & Survey Period & Operative Range & Reference \\
\hline RTS & Whymper Serac & October 2010-in activity & $4800 \mathrm{~m}$ & [35] \\
\hline GNSS & Whymper Serac & October 2010-2012 & - & [46] \\
\hline TLC & Montitaz Lobe & August 2013-in activity & $3800 \mathrm{~m}$ & {$[37,40]$} \\
\hline TLC & Whymper Serac & August 2016-in activity & $4800 \mathrm{~m}$ & [41] \\
\hline TRI & Montitaz Lobe & $\begin{array}{l}9 \text { August } 2013(2 \mathrm{~h}) \\
7 \text { August } 2014(2 \mathrm{~h})\end{array}$ & $2500 \mathrm{~m} / 3800 \mathrm{~m}$ * & [47] \\
\hline TRI & Whymper Serac & $\begin{array}{l}9 \text { August } 2013(2 \mathrm{~h}) \\
8 \text { August } 2014(3 \mathrm{~h})\end{array}$ & $4800 \mathrm{~m} / 5400 \mathrm{~m} *$ & [47] \\
\hline TRI & Montitaz Lobe & 2 September-14 October 2015 & $2500 \mathrm{~m}$ & {$[38]$} \\
\hline TRI & Montitaz Lobe & 13-19 June 2016 & $2500 \mathrm{~m}$ & \\
\hline TRI & Montitaz Lobe & 26 September 2019-in activity & $2500 \mathrm{~m}$ & \\
\hline TRI & Whymper Serac & 16 January 2020 -in activity & $4800 \mathrm{~m}$ & \\
\hline
\end{tabular}

* Operative range in terms of distance from Planpincieux hamlet/Mont de La Saxe crest.

\subsection{Robotic Total Station}

An RTS Leica TM30 was installed in the Planpincieux hamlet in 2010 (Figure 1) to monitor the WS, acquiring a measurement every $2 \mathrm{~h}$. The WS is approximately $4800 \mathrm{~m}$ distant from the RTS and the elevation difference is $2400 \mathrm{~m}$. This distance is beyond the declared operational range for the automatic target recognition acquisition mode, which is $3000 \mathrm{~m}$ for standard prisms (Leica TM30 technical data [48]). For this reason, often, not all targets were detected during a single measurement session. The declared accuracy by the manufacturer at the distance of $4800 \mathrm{~m}$ is approximately $8 \mathrm{~mm}$.

A network of several prisms (with an optimal view angle of $40^{\circ}$ for both the horizontal and vertical axes) has been arranged on the WS with the aid of alpine guides (Figure 2). To minimize the risk of losing the prism visibility for the tilting/rotation of the supporting pole, we adopted V-shaped bars that prevent the rotation along the z-axis; furthermore, in October of 2020 we installed a prism with $360^{\circ}$ and $120^{\circ}$ view angles along the $z$ - and $\mathrm{x}$-axes, respectively. Due to logistic difficulties, only two reference prisms were installed in the surrounding bedrock. The exceptional high-mountain conditions caused a frequent loss of prisms, and in-field interventions to replace or substitute missing targets were often necessary. A total of 42 prisms have been installed on the WS surface since 2010. Over this period, on average, $2-5$ prisms were concurrently present. The RTS collected more than 26,000 measurement epochs and approximately 15,000 had at least one reference prism available. The RTS dataset of the WS is likely one of the longest continuous time series of a glacier worldwide.

The extreme weather conditions and the critical operational range introduced high noise to the RTS measurement. To analyze the RTS data before the 2014 break-off, Faillettaz and others (2016) used a robust method to filter most of the artefacts in the data [49]. 


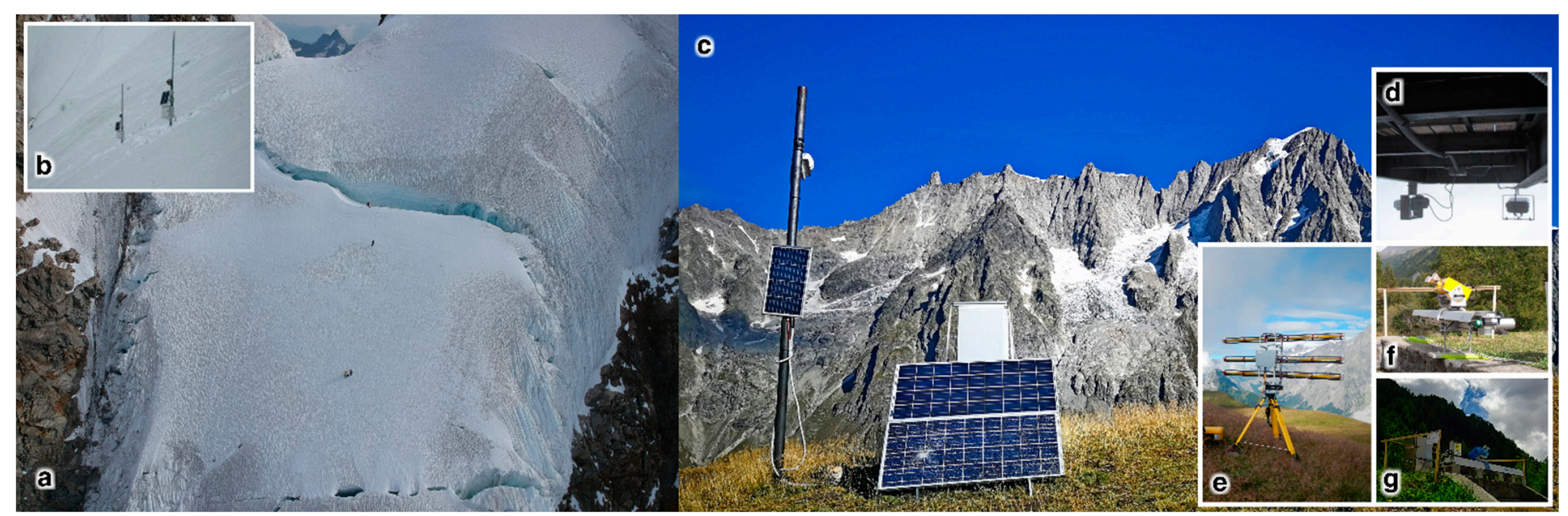

Figure 2. (a) Alpine guides install reflective prisms onto the Whymper Serac on 5 March 2020. (b) GNSS equipped with datalogger, solar panels, and batteries [46]. Reflective prisms were placed on the metallic bars that supported the GNSS for comparison. (c) TLC station that monitors the Montitaz Lobe, with the Planpincieux and Grandes Jorasses glaciers visible in the background. (d) TLC station that monitors the Whymper Serac from Pointe Helbronner. (e-g) the RAR GPRI and the GBSARs IBIS-L and FastGBSAR, respectively.

\subsection{GNSS}

Within the GlaRiskAlp project (http:/ / www.glariskalp.eu/ accessed on 1 February 2021) [46], three prototypal GNSS were installed on the WS surface (Figure 2) in October 2010 and remained operative until 2012. Low-cost, single-channel receivers were adopted (AC12 Magellan), as break-offs, snow avalanches, and intense snowfall could have caused their loss. Each device was equipped with a solar panel, a small backup battery and a prototypal datalogger. The stored data were Wi-Fi transmitted to a radio repeater every $30 \mathrm{~min}$, which was connected to the processing station in the Planpincieux hamlet [50]. The GNSS was acquired every $15 \mathrm{~s}$ and the data were processed using the differential GPS method, using three GNSS reference receivers located in the Ferret Valley. Unfortunately, serious hardware issues and the snow cover strongly limited correct data acquisition. Nevertheless, between July 2011 and January 2012, the data quality was satisfactory.

\subsection{Time-Lapse Imagery}

Time-lapse cameras (TLCs) were installed in August 2013 and 2016 to monitor the ML [40] and WS, respectively. The TLCs were placed on the Mont de La Saxe crest $(2300 \mathrm{~m}$ a.s.1.) and at Pointe Helbronner (3400 m a.s.1.) (Figure 1). The TLC distances from the respective glaciers are approximately $3800 \mathrm{~m}$ and $4800 \mathrm{~m}$, respectively.

The monitoring station of ML (Figure 2) comprises a UMTS modem, a DSLR Canon EOS 700D equipped with a 297 mm-lens (another TLC targets the Planpincieux Glacier with 120 mm-lens), a Raspberry-Pi 3 computer, a fan heater, a power module composed of several solar panels and a backup battery and two surveying webcams. The TLCs are mounted on a cemented pillar independent from the shelter box. This allows minimum misregistration, even in the presence of strong wind. Occasionally, bad weather and snow cover cause system stand-by, but it reactivates autonomously. The monitoring station is completely autonomous, and it is remotely accessible. The TLCs acquire with hourly frequency and the images are transmitted using a UMTS connection. We experimented with both auto and manual focus modalities for image acquisition. The advantage of the former solution is that, in general, the photographs are sharper, while using manual focus they are frequently blurred. On the other hand, autofocus can fail in the presence of slight condensation on the viewing window. To solve this issue, we equipped the monitoring station with a fan heater that eliminates the condensation. In the end, we opted for the autofocus acquisition mode, because image blurring affects DIC results [51]. Since DIC suffers surface shadow pattern change [22,52], we implemented an automatic machine 
learning-based procedure to autonomously select and process the images acquired in diffuse illumination conditions [23]. Thereby, we strongly reduced the human efforts required to monitor the glacier continuously. During the years 2014-2019, we applied the DIC using the spatial cross-correlation calculated in the Fourier space. In 2020, we adopted the zero-mean normalized cross-correlation metrics. This latter method is computationally demanding, but it is less affected by environmental noise [51].

The TLC that targets the WS is a DSLR Canon EOS 1200D equipped with a $400 \mathrm{~mm}$ lens. The TLC acquires photos in auto-focus mode. The monitoring system is connected to the power grid and transmits, depending on the season, one to four images per hour via a WiFi connection. The shelter box is mounted on the metallic pillars of the Skyway cable car station of Pointe Helbronner. We observed strong image misregistration. The image registration was hampered by the presence/absence of snow on the stable surfaces that were adopted as reference. To partially reduce this hindrance, we adopted the cosine similarity method [51], which proved to be less affected by this issue.

The pixel footprints of the TLCs are approximately $54 \mathrm{~mm} \mathrm{px}^{-1}$ and $52 \mathrm{~mm} \mathrm{px}^{-1}$ (ML and WS images, respectively).

The TLC that monitors the ML acquired more than 23,500 photographs between August 2013 and December 2020, while that of the WS acquired more than 10,500 images between August 2016 and December 2020. The time-lapse time series of ML and WS are among the longest continuous glaciological TLC surveys worldwide.

\subsection{Terrestrial Radar Interferometry}

In the Grandes Jorasses area, six experimental TRI campaigns have been conducted since 2013. Among the different typologies of TRI apparatuses, three models of GBSAR: IBIS-L (IDS GeoRadar), FastGBSAR (Metasensing), and GBinSAR LiSALab (LiSALab), and one RAR: GPRI (Gamma Remote Sensing), were adopted (Figure 2). All the radars operated in Ku-band and provided VV polarisation; FastGBSAR additionally had fully polarimetric capability.

All radars were installed in the Planpincieux hamlet to have the apparatuses connected to the power grid. The distances from ML and WS were of $2500 \mathrm{~m}$ and $4800 \mathrm{~m}$, respectively. Using the RAR, we also experimented with the positioning on the Mont de La Saxe crest, near the TLC monitoring system of the ML (Figure 1). In this case, the sensor-to-distance increased (Table 1).

The exceptional mountain environment introduced a series of data processing issues $[29,31]$. The variable atmospheric conditions and the large elevation difference caused a strong disturbance. Liquid and solid precipitation modified the surface scattering properties and caused data degradation. Therefore, we implemented specific methods to minimize the atmospheric effects and to remove corrupted data effectively [38]. A further critical issue concerned the sensor-to-target distance. GBSAR devices have a limited operational range, up to $4-5 \mathrm{~km}$. Therefore, ad hoc software/hardware adjustments were applied to monitor WS, e.g., the adoption of high-gain antennas. The long distances also affected the results' spatial resolution. The azimuth resolution linearly decreases with the range. Using the GBSARs, the resolution was approximately 10-15 m for ML and 15-20 m for WS. Unlike the GBSAR systems, the RAR suffered the operational range less, due to its higher SNR, but its azimuth resolution was twice as coarse.

Another issue concerned the radargrams' georeferencing, which was fundamental to evaluate the active glacier portions precisely. Therefore, we proposed a method based on the spatial correlation between amplitude maps and a digital terrain model, obtaining high georeferencing precision [39].

\subsection{Data Integration}

Besides the independent analysis of single monitoring data, we implemented data integration methods. The use of many systems surveying the same area provided data redundancy that served multiple scopes. First, the data were validated to strengthen 
their reliability and to recognize potential outliers. Second, the probability of losing data because of system failure was reduced. Third, each surveying sensor detected different components of surface displacement. This allowed for the development of a technique to fuse the DIC and TRI results [39]. Since DIC and TRI detect complementary displacement components, their merging provided the spatially distributed three-dimensional surface kinematics. The procedure involved first the radar data geocoding, which was conducted by applying a spatial correlation between the DTM and the radar amplitude map, and the orthorectification of the oblique image, using recognizable natural features on both the photographs and the available DTM as ground-control points. Second, the measurement data of both instruments were projected into a common coordinate system (CS) by applying three-dimensional rototranslation.

Finally, the independent displacement components were summed to obtain the threedimensional displacement vector. In our case, we projected the TRI data onto the images of CS and we summed the projected LOS-parallel displacement component with the two displacement components orthogonal to the LOS obtained with the DIC.

\section{Results}

\subsection{Robotic Total Station and GNSS}

In this section, we present the results of the topographic network installed on the WS. As mentioned before, the GNSS installed in 2010 suffered technical failures that reduced the number of correct acquisitions. However, in the period between July 2011 and January 2012, the GNSS provided displacement values in good agreement with the RTS data between July-December 2011 and (monthly averages have correlation coefficient 0.73 , $p$-value $<10^{-4}$ and mean absolute difference $4.5 \mathrm{~mm} \mathrm{day}^{-1}$ ) (Figure 3) [46].

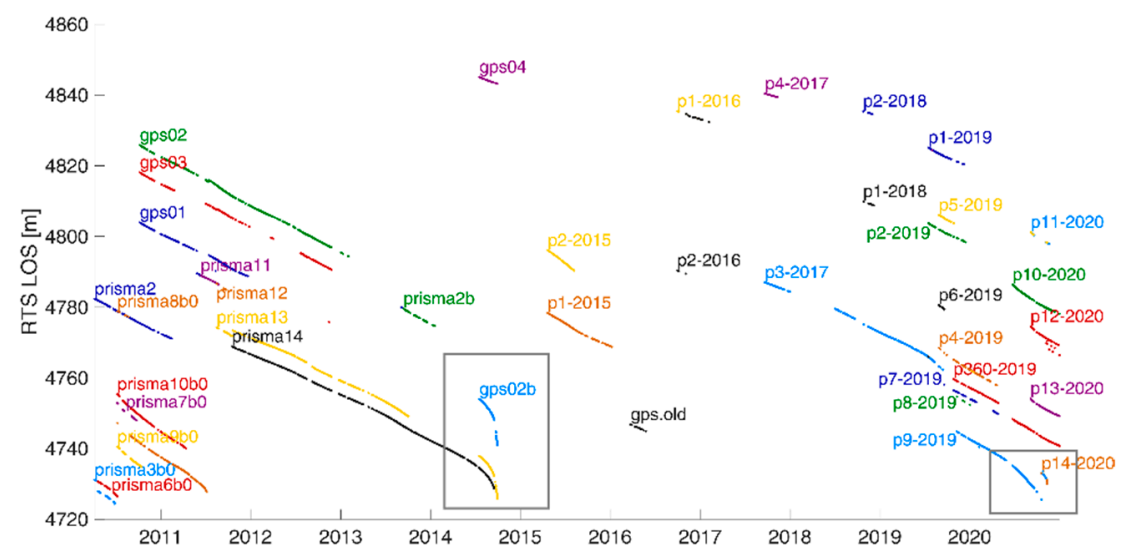

Figure 3. Reflective prisms installed onto the WS since 2010. The labels "gps" refer to prisms too. The ordinates report the evolution of the distance between every prism and the RTS. In September 2014 and November 2020, the acceleration of several prisms is visible in the grey boxes, which corresponds to ice break-offs.

The analysis of RTS data showed that the usual WS surface velocity follows a seasonal trend. This velocity varies between $\sim 20-30 \mathrm{~mm} \mathrm{day}^{-1}$ in the cold season and $40-50 \mathrm{~mm} \mathrm{day}^{-1}$ during the warm period (Figure 3) [45]. The RTS time series of the second halves of 2014 and 2020 showed the serac acceleration before the ice break-offs that occurred on 23 and 29 September 2014 and 17 October and 11 November 2020 (Figure 4). 


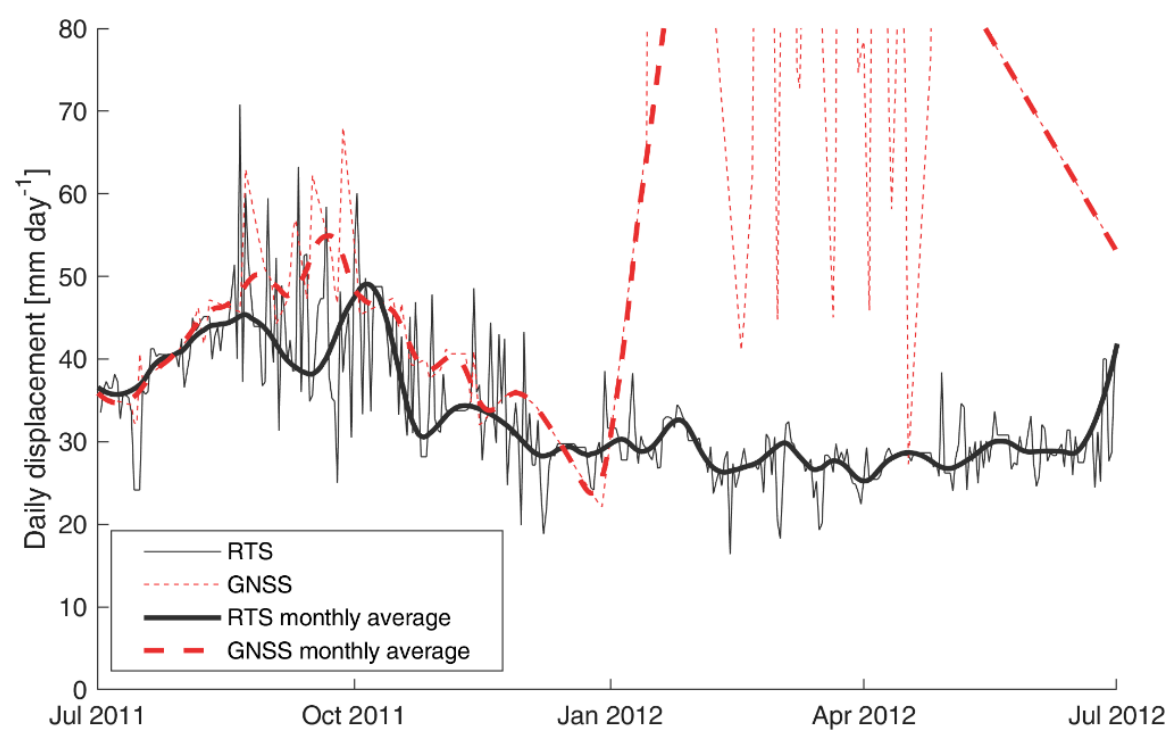

Figure 4. Whymper Serac's daily surface 3D displacement measured by GNSS (dashed red line) and RTS (solid black line). Thick lines refer to the monthly averages. The displacement values are the averaged values of the available three GNSS and three to five RTS measured prisms.

The displacement trend in 2014 followed the combination of power-law and logoscillation behavior proposed by Pralong et al. [53]. Integrating this method in data postprocessing, Faillettaz et al. [35] showed that it would be possible to predict the instant of failure almost two weeks before the event.

\subsection{Time-Lapse Camera}

Commonly, monitoring with the DIC technique provides at most daily kinematic maps, because the processed images should be acquired with similar illumination conditions. Such a temporal frequency is sufficient to detect relatively fast processes. For example, we observed a few periods of strong acceleration of the ML every year, culminating with relatively large break-offs [37]. Such a phenomenon has a temporal development of 5-10 days (Figure 5).

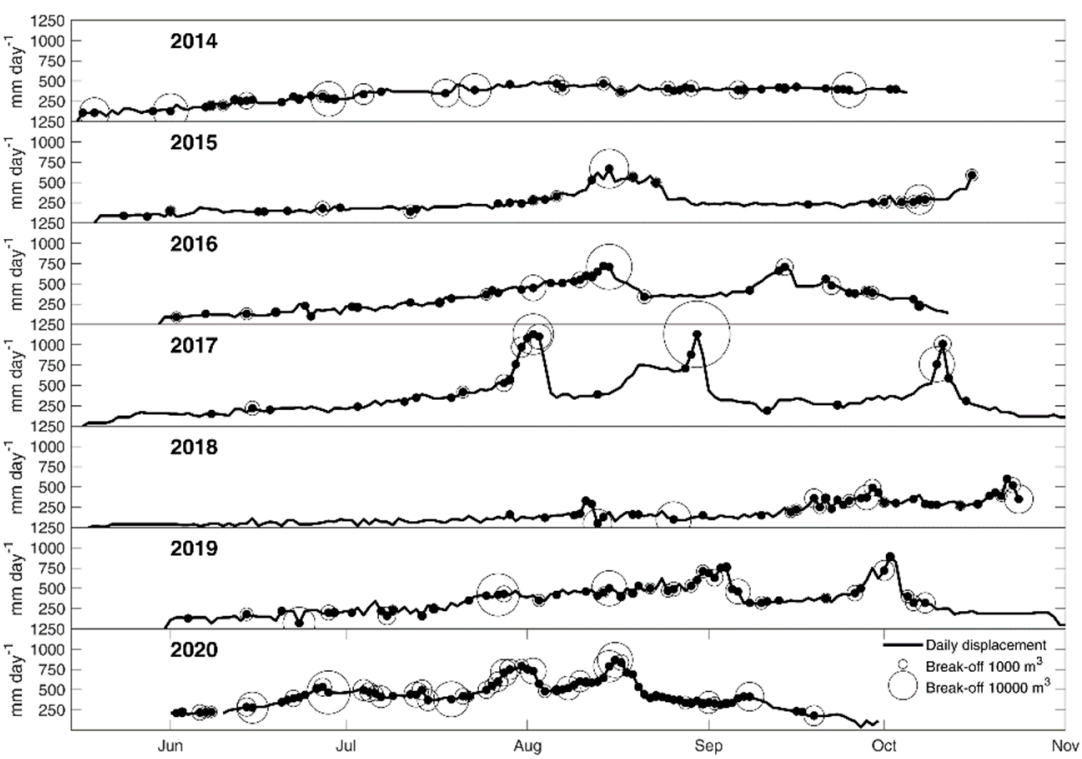

Figure 5. DIC time series of the daily velocity of the ML snout. The solid black circles represent the break-offs, while the white circle size is proportional to the break-off volume. Modified from [37]. 
Moreover, the analysis of surface displacement maps and the photographs' visual investigation permitted the identification of potentially unstable sectors. In the Summer of 2019 and 2020, we identified wide fractures that isolated ice portions characterized by notable acceleration. These portions had an estimated volume of $250,000 \mathrm{~m}^{3}$ and $500,000 \mathrm{~m}^{3}$ [54]. Run out simulations showed that potential break-offs could have reached the Planpincieux hamlet [55]. Emergency plans were activated, but fortunately, large collapses did not occur.

Besides the kinematics measurement, the availability of high-frequency images allowed the identification and classification of the break-offs from the ML snout. Three main processes usually cause collapses: (i) disaggregation: detachments of relatively small ice fragments (volume $<10^{3} \mathrm{~m}^{3}$ ); (ii) water tunnelling: collapse due to the outburst of water pockets and/or collapse of the empty cavities; and (iii) slab failure: detachment of large ice lamella due to development of a fracture along the entire ice thickness (volume $>10^{4} \mathrm{~m}^{3}$ ). The largest break-off was observed on 29 August 2017 with a volume of approximately $55,000 \mathrm{~m}^{3}$ [37].

In 2020, we applied the DIC processing to the photographs of the WS. The expected motion was approximately $20-50 \mathrm{~mm}^{-1 a y}{ }^{-1}$, which corresponded to less than one pixel. We applied the DIC processing to images separated by time gaps of a few days to a couple of weeks to ensure larger SNR. Such an approach allowed us to observe the acceleration of the ice chunks that collapsed on 17 October and 11 November 2020 (Figure 6).
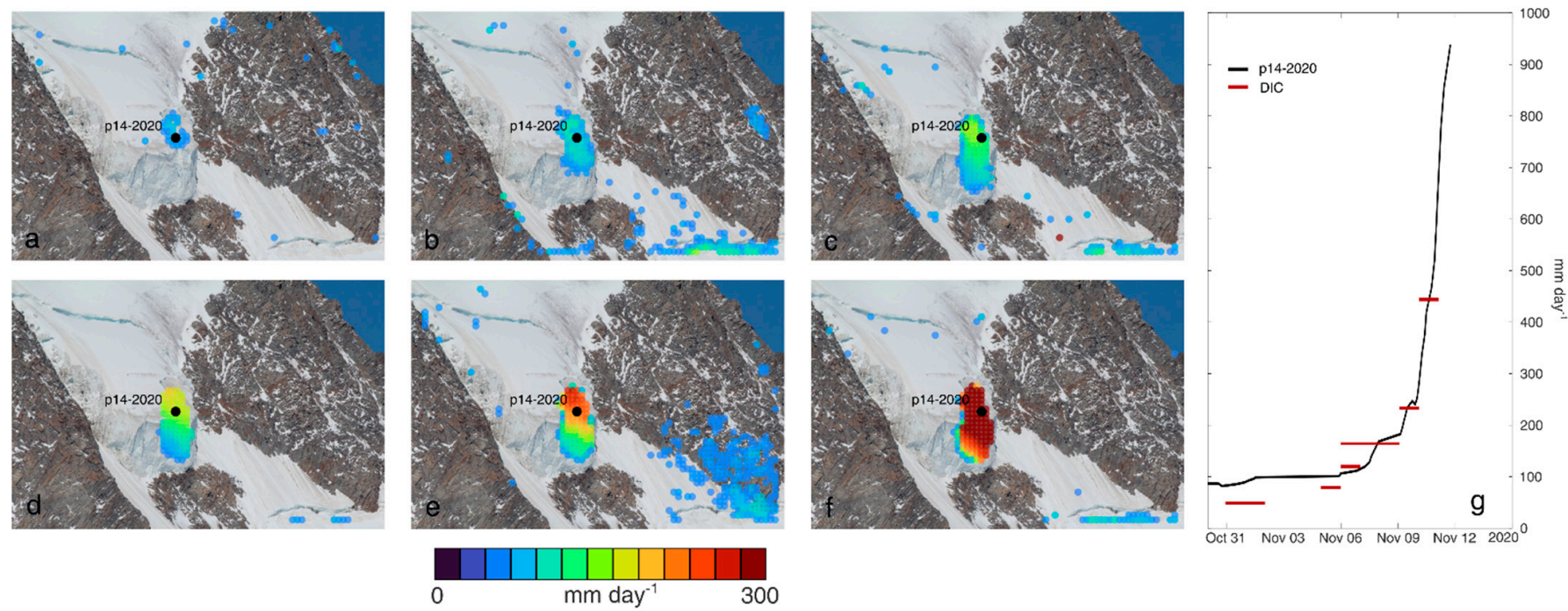

Oct 31 Nov 03 Nov 06 Nov 09 Nov $122020^{\circ}$

Figure 6. (a-f) Mean daily velocity (calculated as the sum of the two displacement components orthogonal to the LOS) of the Whymper Serac measured with DIC. The results were obtained by processing the images between 31 October-2 November; 5-6 November; 6-7 November; 6-9 November; 9-10 November; and 10-11 November 2020, respectively. (g) The black line refers to the velocity of the prism p14-2020 that was placed onto the surface of the ice chunk of approximately $20,000 \mathrm{~m}^{3}$ that broke-off on 11 November 2020, while the horizontal red lines indicate the mean daily velocity obtained with the DIC in correspondence of the prism. Both DIC and RTS data evidenced the acceleration of the ice chunk. The height of the serac face is approximately $40 \mathrm{~m}$.

\subsection{Terrestrial Radar Interferometry}

The experimental campaigns conducted between 2013 and 2016 were used to assess the limits and potentiality of the TRI in surveying the Grandes Jorasses glaciers. During the RAR campaigns in 2013 and 2014, we examined the influence of radar positioning (Figure 1). The installation in the Planpincieux hamlet offered a LOS perspective almost parallel to the displacement direction. Therefore, the measured displacement represented most of the real movement. However, the visibility of glacier portions was limited.

Conversely, almost the whole glaciated area was detectable from the crest of Mont de La Saxe, but a lower fraction of the actual displacement was observed due to the higher 
angle between the LOS and the main motion direction. Figure 7 shows the surface velocity maps of the surveys of 7 and 8 August 2014. In the areas visible by both radar positions, one can note the difference in measured velocities due to the different LOS orientations.

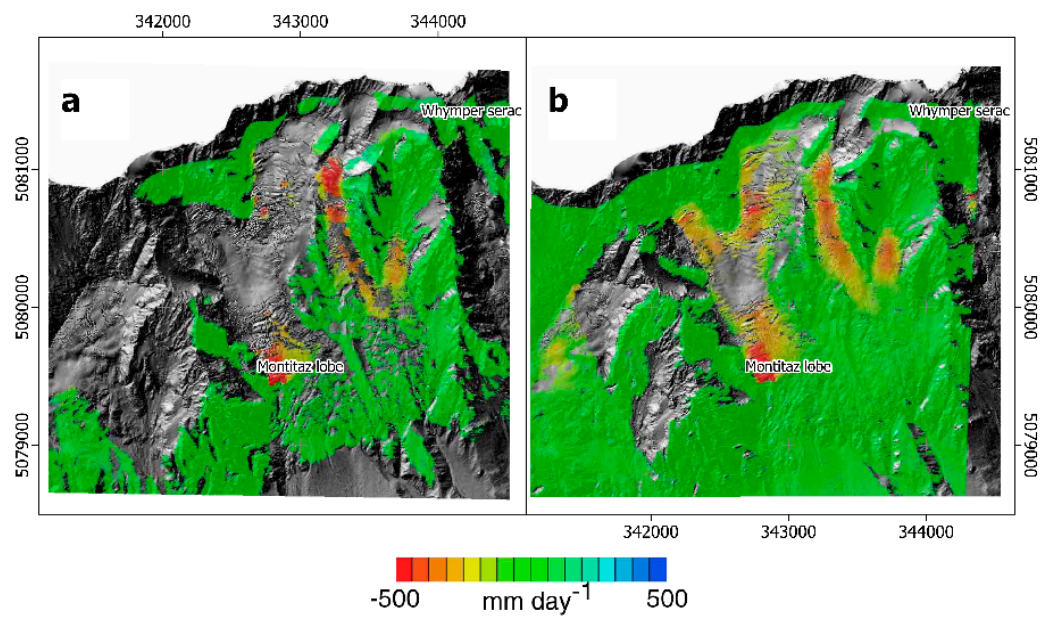

Figure 7. Velocity maps obtained with terrestrial interferometric radar installed (a) in the Planpincieux hamlet and (b) on the opposite ridge of the valley. The two campaigns lasted for $2 \mathrm{~h}$ and were conducted on 7 and 8 August 2014, respectively. Modified from [47].

In 2015, the measurements were conducted with an acquisition frequency of approximately $15 \mathrm{~min}$. In that period, the daily glacier displacement was of the order of $400-500 \mathrm{~mm} \mathrm{day}^{-1}$. The Ku-band adopted radar had a maximum detectable displacement capability between two acquisitions of $8.5 \mathrm{~mm}$, which corresponded approximately to $400 \mathrm{~mm} \mathrm{day}^{-1}$, i.e., comparable to the glacier velocity. Therefore, phase wrapping often occurred. To avoid it, we adopted a shorter temporal baseline in the subsequent surveys.

In 2016, we conducted a campaign with an acquisition frequency of $10 \mathrm{~s}$. This allowed us to minimize the atmospheric disturbance and to avoid phase ambiguity. However, the signal amplitude was low due to the shorter duration of the acquisition, thus, the surveyed area was reduced. Additionally, we explored the possible application of different polarimetric configurations, which help in land cover classification [56]. Unfortunately, the quality of the results was low, likely because the $\mathrm{Ku}$ band is not suitable for polarimetric measurements on temperate glaciers, as also observed by Baffelli et al. [57].

Since September 2019 and January 2020, two permanent GBSARs have been arranged to survey the ML and WS, respectively. These monitoring systems are still in activity and serve early warning purposes. For legal reasons, the possibility of publishing their data is limited.

\subsection{Data Integration}

The concurrent use of various surveying systems provided data redundancy that minimized data loss. Figure 6 shows the WS daily velocity obtained with DIC and RTS. As one can note, the DIC data were not continuous, while the RTS acquired several epochs every day. However, their integration provided wider information on the glacier kinematics. Since DIC detected spatially distributed data, it was possible to observe the vertical gradient of the ice chunk motion before the break-off. On the other hand, using only RTS data, such a toppling process could not have been observed. It is worth noting that the RTS displacement values were higher than the DIC ones. This happened because the RTS detected three-dimensional displacement, while the DIC detected only the two displacement components orthogonal to its LOS.

Another advantage of data integration is the measurement validation. During AprilMay 2020, TRI, DIC, and RTS observed different velocity trends to the WS. The RTS detected an acceleration because the reflective prism was located on an ice chunk isolated from the main serac body, while the TRI measured an overall deceleration. Analyzing the DIC 
results, we noticed the presence of an isolated ice chunk, while the rest of the serac was constantly moving. Additionally, the TRI data were probably affected by atmospheric artefacts, which were corrected using the other sensors' data for calibration.

Another developed data integration approach was the coupling of TRI and DIC measurements. We tested this method between 4 and 27 September 2015 and in the 2020 warm season (Figure 8) [39]. In these cases, we used a GBSAR installed in the Planpincieux hamlet and the TLC of the Mont de La Saxe (Figure 1). The data coupling provided spatially distributed three-dimensional surface kinematics in the areas visible by both apparatuses, which depended on the positioning of the monitoring systems. These three-dimensional displacement maps allowed us to observe that the motion direction was not uniformly parallel to the local slope. The steep faces of the seracs moved as a single rigid body showing a relevant horizontal component of the movement [39].

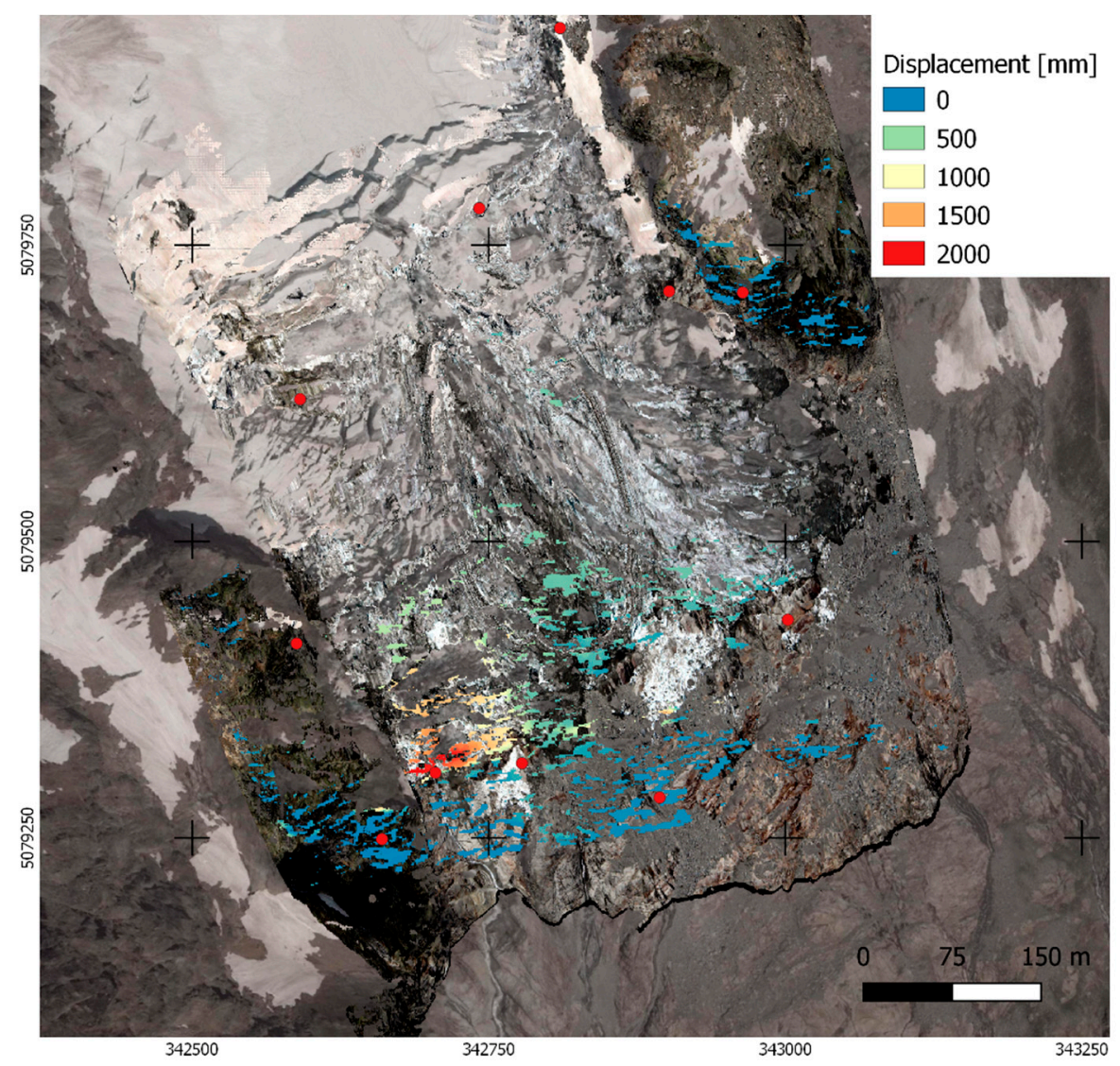

Figure 8. Three-dimensional daily displacement of the Planpincieux glacier between 31 July and 1 August 2020 obtained from the fusion of DIC and TRI results. The orthorectified oblique photographs is overlain on a Google Earth image. The red dots indicate the ground control points adopted to orthorectify the oblique picture.

\subsection{Uncertainty Analysis}

The GNSS uncertainty was estimated during field tests. The GNSS were deployed in two different positions, which were measured for periods of two hours each. The residuals adopted as reference had a standard deviation of $20 \mathrm{~mm}$ compared with the measurement of a total station.

We estimated the measurement uncertainty of the other monitoring systems according to the following approach: we examined the displacement calculated on the stable areas, which is assumed to be null, and we considered the standard deviation of the residuals as the uncertainty.

In the case of RTS, we considered the corrected values of the reference prisms since 2010, whose standard deviation was $106 \mathrm{~mm}$. 
We calculated the uncertainty of DIC applied to ML and WS photographs separately. For ML, we considered the daily displacement measured in bedrock areas between 4 and 27 September 2015 (11,700 points), while for WS, we used the dataset shown in Figure 6 (5600 points). For these datasets, we obtained a standard deviation of $18 \mathrm{~mm}$ and $17 \mathrm{~mm}$, respectively. However, in WS, misregistration caused large errors, thus, the corresponding uncertainty refers only to the measurement obtained in optimal conditions.

In the case of the GBSAR, we considered 6300 measurements between 4-27 September 2015. These data were acquired every $15 \mathrm{~min}$ on a rocky area. For this dataset, we obtained a standard deviation of $1 \mathrm{~mm}$.

Concerning the DIC-TRI fusion, a source of error pertained to the data georeferencing. We estimated a geocoding uncertainty between $1-2 \mathrm{~m}$ and $\sim 4 \mathrm{~m}$ for the DIC and TRI results [39].

\section{Discussion}

The monitoring systems adopted in the Grandes Jorasses glacial complex cover most of the existing terrestrial apparatuses to survey the surface glacier kinematics:, i.e., RTS, GNSS, TLC, and terrestrial radar interferometer. Such a wide range of sensors in a limited area makes the Grandes Jorasses an open-air laboratory, where the limits and potentialities of monitoring systems in an environment with extreme weather, accessibility, and geometric characteristics can be explored. Table 2 summarizes the main characteristics of every monitoring system, as well as their main advantages and limitations.

Table 2. Main characteristics, advantages, and limitations of the considered survey systems.

\begin{tabular}{|c|c|c|c|c|c|c|}
\hline $\begin{array}{l}\text { Survey } \\
\text { System }\end{array}$ & Measurement & $\begin{array}{l}\text { Measurement } \\
\text { Uncertainty }\end{array}$ & $\begin{array}{l}\text { Acquisition } \\
\text { Frequency }\end{array}$ & $\begin{array}{l}\text { Financial } \\
\text { Cost }\left[10^{3} €\right]\end{array}$ & Advantages & Limitations \\
\hline RTS & $\begin{array}{l}\text { Point 3D } \\
\text { displacement }\end{array}$ & $\sim 100 \mathrm{~mm}$ & Hour & $30-50$ & Long-life & $\begin{array}{l}\text { Uncertainty increasing with } \\
\text { range } \\
\text { Need for on-site access } \\
\text { Weather sensitive }\end{array}$ \\
\hline GNSS & $\begin{array}{l}\text { Point 3D } \\
\text { displacement }\end{array}$ & $\sim 20 \mathrm{~mm}$ & Hour & 1-10 each & $\begin{array}{l}\text { Continuous survey } \\
\text { Weather insensitive }\end{array}$ & $\begin{array}{l}\text { Need for on-site access } \\
\text { Need for on-site power supply } \\
\text { Possible sensor loss }\end{array}$ \\
\hline TLC & $\begin{array}{l}\text { Area 2D } \\
\text { components } \\
\text { orthogonal to LOS }\end{array}$ & $\sim 20 \mathrm{~mm}$ & Day & $5-10$ & $\begin{array}{l}\text { Low-cost } \\
\text { Long life } \\
\text { Remote sensing }\end{array}$ & $\begin{array}{l}\text { Low sensitivity } \\
\text { Weather sensitive } \\
\text { No nocturnal acquisition } \\
\text { Non-geocoded measurement }\end{array}$ \\
\hline TRI & $\begin{array}{l}\text { Area 1D component } \\
\text { parallel to LOS }\end{array}$ & $\sim 1 \mathrm{~mm}$ & Minute & $150-350$ & $\begin{array}{l}\text { High acquisition frequency } \\
\text { Continuous survey } \\
\text { Remote sensing }\end{array}$ & $\begin{array}{l}\text { Expensive } \\
\text { Complex processing } \\
\text { Difficult logistics }\end{array}$ \\
\hline
\end{tabular}

The RTS provided punctual, three-dimensional measurements with millimetric sensitivity. The RTS technology is consolidated, and its limitations and advantages are known. In optimal conditions, it offers continuous hourly data. The RTS requires little processing effort and has good endurance and reliability. The network's financial cost is mainly related to the instrument, whose price is in the range of 20,000-40,000 $€$; the cost of the targets is negligible. The principal disadvantage of this system is the need for physical installation and maintenance of passive targets in the investigated area. This can be impossible in inaccessible areas like the ML, or very challenging, like in the WS, where the support of alpine guides is necessary. The data continuity may be hampered by target loss or by small changes in the view angle of the reflective prisms caused by strong wind, avalanches, or rapid glacier movement. All these factors can prevent target localization by the RTS. Therefore, target replacement is often necessary. A possible solution is the use of prisms with a full view angle (i.e., $360^{\circ}$ on the vertical axis and $120^{\circ}$ on the horizontal axis). However, the cost of such a prism is in the order of $1000 €$. Moreover, severe weather may hinder the survey, especially when the sensor-to-target distance is high. In the Grandes Jorasses case, the RTS measurement uncertainty is high (approximately $100 \mathrm{~mm}$ ). A robust network of reference prisms should solve this issue; however, this could be challenging to achieve in 
exceptional contexts such as WS. Despite its limitations, the RTS of the WS proved to be an effective solution for continuous monitoring. This RTS system, active since 2010, allowed for the identification of precursors of the collapses of 2014 and 2020 [35], thus confirming its suitability for warning purposes.

GNSS share some peculiarities with the RTS. They also provide punctual, highfrequency, three-dimensional measurements with millimetric sensitivity. Additionally, they acquire data in every meteorological condition. An important GNSS advantage is that they do not require direct visibility from the master station because they are connected to it using radio protocol. In the case of WS, visibility is one of the most serious limitations of acquisition continuity. The cost of high-performing multi-channel GNSS can reach up to $10,000 €$ per device. Therefore, a potential sensor loss represents a relevant financial waste. However, low-cost solutions can be adopted with acceptable reliability [58], as in the case of WS, where the cost of a single GNSS was approximately $1000 €$, including the power supply and the data transmission equipment [50]. GNSS, like the RTS, require direct access to the investigated area for the receiver installation. However, GNSS sensor maintenance has to be done on site, requiring further efforts, particularly if installed in areas not easy to reach with bad meteorological conditions. Moreover, the need for an autonomous power supply is an additional constraint of this system, making it a less robust solution.

The TLC provided a photographic dataset that facilitates the phenomena investigation, such as the break-off and fracture identification and the instability process evolution. The operational distance can easily reach several $\mathrm{km}$ with the adoption of entry-level equipment. In addition, the adoption of the DIC technique offers spatially distributed two-dimensional maps of surface kinematics. The data's spatial resolution depends on the adopted hardware, the sensor-to-target distance, and the processing parameters. Spatial data facilitate the understanding of the investigated process. For example, in the ML, we identified different kinematic domains, which corresponded to potentially unstable sectors [37], while in WS, we observed the toppling process before the break-off occurred on 11 November 2020 (Figure 6). The DIC uncertainty is sub-pixel in optimal conditions, which corresponded to less than $20 \mathrm{~mm}$ in ML and WS cases. However, snow pattern changes hamper co-registration and measurement. Reliable results are obtained only with favorable weather and suitable illumination conditions. Moreover, the temporal baseline should correspond to a displacement of a few pixels to enhance the SNR. Consequently, the optimal temporal frequency is to process one image per day. The occurrence of bad weather can limit the number of usable images and increase the time gaps between the images suitable for processing [59]. Nevertheless, such periods rarely last more than several days. Such a frequency is usually sufficient to observe rapid glaciological phenomena successfully. For example, we observed the speed-up phases of the ML snout, which lasted several days (Figure 5), or the acceleration of the collapsed ice chunk in the WS on 11 November 2020 (Figure 6). A TLC monitoring system has a high benefit-cost ratio thanks to the photographic time-lapse dataset's characteristics and the financial costs of the involved equipment (approximately 5000-10,000 €). It is suitable to investigate rapid glacial processes and, to a lesser extent, it can help in warning activities, even though it cannot be a primary tool for this purpose, because it operates at daily temporal frequency and needs favorable weather to provide results.

TRI offers spatially distributed maps of the displacement component that is parallel to the LOS. The apparatus positioning has to be carefully identified to maximize the displacement fraction that can be measured. Terrestrial radars have the advantage of operating continuously with minute frequency, even in the presence of unfavorable weather. TRI measurements have millimeter uncertainty, but they are sensitive to many sources of noise. In glacial areas, environmental disturbances complicate the data processing. The results interpretation is not trivial, and specific expertise is necessary. Elevated sensor-totarget distances coarsen the spatial resolution and may require non-standard hardware. The equipment is cumbersome and power demanding; consequently, logistic efforts are necessary. Additionally, the financial costs of the apparatus are relevant and vary from 
$150,000 €$ to $350,000 €$. Despite these limitations, a terrestrial radar interferometer is the best performing solution for continuous near-real-time monitoring that is also suitable for early warning purposes. For this reason, in the Winter of 2019/2020, two permanent GBSARs were arranged to survey the ML and WS for early warning purposes. In these cases, the TRI technique was adopted due to its measurement capability in every meteorological condition and its high temporal frequency.

Finally, we showed that the concurrent adoption of different monitoring systems has various advantages. First, it avoids data loss in the case of a single system failure; second, it provides data redundancy for measurement validation; third, it allows DIC and TRI data coupling to obtain the three-dimensional surface kinematics.

\section{Conclusions}

The Grandes Jorasses glacial complex comprises different typologies of glaciers located close to a touristic area. Two sectors of these glaciers (i.e., the ML and the WS) menace the population due to regular break-offs that could reach hundreds of thousands of cubic meters. In the last decade, a complex monitoring network has been arranged to enhance our understanding of the glacier dynamics and control their evolution to identify potential failure precursors.

We presented several strategies adopted to monitor the WS and ML. In the last decade, we conducted surveys employing a wide range of sensors that detected the surface kinematic. In particular, this paper presented the use of RTS, GNSS, TLC, and TRI. We reported the most relevant results obtained and illustrated the main potentialities and limits of the single monitoring apparatuses. We discussed their possible uses in the complex and challenging glacial environment. Limited accessibility, bad weather conditions, low temperatures, and the need for long-range measurement systems make glacier monitoring a critical challenge from the technical point of view. The open-air laboratory of the Grandes Jorasses offers the opportunity to develop and test different monitoring solutions.

Considering the aims of process investigation and warning activities, we showed that warning systems should acquire data in every meteorological condition and early warning can be achieved only by using apparatuses that provide near-real-time data. Therefore, TRI is likely the best approach, even though it requires high financial costs. In simpler contexts, RTS and GNSS have often been adopted for early warning due to their lower financial cost. Nevertheless, logistic issues of accessibility and maintenance are critical elements in the WS and the extreme weather and geometry do not guarantee data continuity. A possible solution is the adoption of redundant monitoring systems to minimize data loss.

Conversely, photographic data allow for an immediate vision of the monitored area. Accordingly, TLC is a valuable tool for understanding glaciological processes. Moreover, the DIC technique produces quantitative displacement results. The combined use of different monitoring systems to acquire complementary data is a promising approach that provides further opportunities for scientific investigation and early warning activities.

Author Contributions: Conceptualization, formal analysis, investigation, writing-original draft, N.D.; conceptualization, supervision, investigation, writing-review and editing, D.G. (Daniele Giordan); investigation, writing-review and editing, F.T.; formal analysis, Writing-Review and editing, A.W.; writing-review and editing, D.G. (Danilo Godone). All authors have read and agreed to the published version of the manuscript.

Funding: This research received no external funding.

Institutional Review Board Statement: Not applicable.

Informed Consent Statement: Not applicable.

Data Availability Statement: Datasets for this research is published in Dematteis et al. (2020) Multisource data of glacier kinematics. 4TU. Centre for Research Data doi:10.4121/uuid:688ae25c0fa0-463c-baf3-34ebdf9fdbd.

Conflicts of Interest: The authors declare no conflict of interest. 


\section{References}

1. Barnett, T.P.; Adam, J.C.; Lettenmaier, D.P. Potential impacts of a warming climate on water availability in snow-dominated regions. Nature 2005, 438, 303-309. [CrossRef]

2. López-Moreno, J.I.; Alonso-González, E.; Monserrat, O.; Del Río, L.M.; Otero, J.; Lapazaran, J.; Luzi, G.; Dematteis, N.; Serreta, A.; Rico, I.; et al. Ground-based remote-sensing techniques for diagnosis of the current state and recent evolution of the Monte Perdido Glacier, Spanish Pyrenees. J. Glaciol. 2019, 65, 85-100. [CrossRef]

3. Deline, P.; Gruber, S.; Delaloye, R.; Fischer, L.; Geertsema, M.; Giardino, M.; Hasler, A.; Kirkbride, M.; Krautblatter, M.; Magnin, F.; et al. Ice Loss and Slope Stability in High-Mountain Regions. In Snow and Ice-Related Hazards, Risks, and Disasters; Academic Press: Cambridge, MA, USA, 2014; pp. 521-561, ISBN 9780123964731.

4. Kääb, A.; Huggel, C.; Fischer, L.; Guex, S.; Paul, F.; Roer, I.; Salzmann, N.; Schlaefli, S.; Schmutz, K.; Schneider, D.; et al. Remote sensing of glacier- and permafrost-related hazards in high mountains: An overview. Nat. Hazards Earth Syst. Sci. 2005, 5, 527-554. [CrossRef]

5. Shugar, D.H.; Jacquemart, M.; Shean, D.; Bhushan, S.; Upadhyay, K.; Sattar, A.; Schwanghart, W.; McBride, S.; de Vries, M.V.W.; Mergili, M.; et al. A massive rock and ice avalanche caused the 2021 disaster at Chamoli, Indian Himalaya. Science 2021, 373, 300-306.

6. Watson, C.S.; Quincey, D. Glacier Movement. In Geomorphological Techniques; British Society for Geomorphology: London, UK, 2015.

7. Luzi, G.; Pieraccini, M.; Mecatti, D.; Noferini, L.; Macaluso, G.; Tamburini, A.; Atzeni, C. Monitoring of an alpine glacier by means of ground-based SAR interferometry. IEEE Geosci. Remote Sens. Lett. 2007, 4, 495-499. [CrossRef]

8. Hewitt, K.; Wake, C.P.; Young, G.J.; David, C. Hydrological investigations at Biafo Glacier, Karakoram range, Himalaya: An important source of water for the Indus River. Ann. Glaciol. 1989, 13, 103-108. [CrossRef]

9. Stocker-Waldhuber, M.; Fischer, A.; Helfricht, K.; Kuhn, M. Long-term records of glacier surface velocities in the Ötztal Alps (Austria). Earth Syst. Sci. Data 2019, 11, 705-715. [CrossRef]

10. Huss, M.; Bauder, A.; Werder, M.; Funk, M.; Hock, R. Glacier-dammed lake outburst events of Gornersee, Switzerland. J. Glaciol. 2007, 53, 189-200. [CrossRef]

11. Sugiyama, S.; Bauder, A.; Weiss, P.; Funk, M. Reversal of ice motion during the outburst of a glacier-dammed lake on Gornergletscher, Switzerland. J. Glaciol. 2007, 53, 172-180. [CrossRef]

12. Diolaiuti, G.; Kirkbride, M.P.; Smiraglia, C.; Benn, D.I.; D'Agata, C.; Nicholson, L. Calving processes and lake evolution at Miage glacier, Mont Blanc, Italian Alps. Ann. Glaciol. 2005, 40, 207-214. [CrossRef]

13. Dunse, T.; Schuler, T.V.; Hagen, J.O.; Reijmer, C.H. Seasonal speed-up of two outlet glaciers of Austfonna, Svalbard, inferred from continuous GPS measurements. Cryosphere 2012, 6, 453-466. [CrossRef]

14. Einarsson, B.; Magnússon, E.; Roberts, M.J.; Pálsson, F.; Thorsteinsson, T.; Jóhannesson, T. A spectrum of jökulhlaup dynamics revealed by GPS measurements of glacier surface motion. Ann. Glaciol. 2016, 57, 47-61. [CrossRef]

15. Manson, R.; Coleman, R.; Morgan, P.; King, M. Ice velocities of the Lambert Glacier from static GPS observations. Earth Planets Sp. 2000, 52, 1031-1036. [CrossRef]

16. Fallourd, R.; Trouvé, E.; Roşu, D.; Vernier, F.; Bolon, P.; Harant, O.; Gay, M.; Bombrun, L.; Vasile, G.; Nicolas, J.M.; et al. Monitoring Temperate Glacier Displacement by Multi-Temporal TerraSAR-X Images and Continuous GPS Measurements. IEEE J. Sel. Top. Appl. Earth Obs. Remote Sens. 2011, 4, 372-386. [CrossRef]

17. Sugiyama, S.; Gudmundsson, G.H. Short-term variations in glacier flow controlled by subglacial water pressure at Lauteraargletscher, Bernese Alps, Switzerland. J. Glaciol. 2004, 50, 353-362. [CrossRef]

18. Evans, A.N. Glacier surface motion computation from digital image séquences. IEEE Trans. Geosci. Remote Sens. 2000, 38, 1064-1072. [CrossRef]

19. Ahn, Y.; Box, J.E. Glacier velocities from time-lapse photos: Technique development and first results from the Extreme Ice Survey (EIS) in Greenland. J. Glaciol. 2010, 56, 723-734. [CrossRef]

20. Brinkerhoff, D.; O’Neel, S. Velocity variations at Columbia Glacier captured by particle filtering of oblique time-lapse images. arXiv 2017, arXiv:1711.05366.

21. Messerli, A.; Grinsted, A. Image georectification and feature tracking toolbox: ImGRAFT. Geosci. Instrum. Methods Data Syst. 2015, 4, 23-34. [CrossRef]

22. Schwalbe, E.; Maas, H.G. The determination of high-resolution spatio-temporal glacier motion fields from time-lapse sequences. Earth Surf. Dyn. 2017, 5, 861-879. [CrossRef]

23. Dematteis, N.; Giordan, D.; Allasia, P. Image Classification for Automated Image Cross-Correlation Applications in the Geosciences. Appl. Sci. 2019, 9, 2357. [CrossRef]

24. Noferini, L.; Mecatti, D.; Macaluso, G.; Pieraccini, M.; Atzeni, C. Monitoring of Belvedere Glacier using a wide angle GB-SAR interferometer. J. Appl. Geophys. 2009, 68, 289-293. [CrossRef]

25. Riesen, P.; Strozzi, T.; Bauder, A.; Wiesmann, A.; Funk, M. Short-term surface ice motion variations measured with a ground-based portable real aperture radar Interferometer. J. Glaciol. 2011, 57, 53-60. [CrossRef]

26. Allstadt, K.E.; Shean, D.E.; Campbell, A.; Fahnestock, M.; Malone, S.D. Observations of seasonal and diurnal glacier velocities at Mount Rainier, Washington, using terrestrial radar interferometry. Cryosphere 2015, 9, 2219-2235. [CrossRef] 
27. Gundersen, R.; Norland, R.; Denby, C.R. Monitoring glacier flow in Ny-Ålesund with a high temporal resolution ground-based interferometric-phased array radar. Polar Res. 2019, 38. [CrossRef]

28. Liu, L.I.N.; Jiang, L.; Sun, Y.Y.; Wang, H.; Sun, Y.Y.; Xu, H. Diurnal fluctuations of glacier surface velocity observed with terrestrial radar interferometry at Laohugou No. 12 Glacier, western Qilian mountains, China. J. Glaciol. 2019, 65, 239-248. [CrossRef]

29. Monserrat, O.; Crosetto, M.; Luzi, G. A review of ground-based SAR interferometry for deformation measurement. ISPRS J. Photogramm. Remote Sens. 2014, 93, 40-48. [CrossRef]

30. Luzi, G.; Pieraccini, M.; Mecatti, D.; Noferini, L.; Guidi, G.; Moia, F.; Atzeni, C. Ground-based radar interferometry for landslides monitoring: Atmospheric and instrumental decorrelation sources on experimental data. IEEE Trans. Geosci. Remote Sens. 2004, 42, 2454-2466. [CrossRef]

31. Luzi, G.; Dematteis, N.; Zucca, F.; Monserrat, O.; Giordan, D.; López-Moreno, J.I. Terrestrial radar interferometry to monitor glaciers with complex atmospheric screen. In Proceedings of the International Geoscience and Remote Sensing Symposium (IGARSS), Valencia, Spain, 22-27 July 2018; pp. 6243-6246.

32. Margreth, S.; Funk, M.; Tobler, D.; Dalban, P.; Meier, L.; Lauper, J. Analysis of the hazard caused by ice avalanches from the hanging glacier on the Eiger west face. Cold Reg. Sci. Technol. 2017, 144, 63-72. [CrossRef]

33. Avian, M.; Bauer, C.; Schlögl, M.; Widhalm, B.; Gutjahr, K.H.; Paster, M.; Hauer, C.; Frießenbichler, M.; Neureiter, A.; Weyss, G.; et al. The status of earth observation techniques in monitoring high mountain environments at the example of Pasterze Glacier, Austria: Data, methods, accuracies, processes, and scales. Remote Sens. 2020, 12, 1251. [CrossRef]

34. De Sanjosé, J.J.; Berenguer, F.; Atkinson, A.D.J.; De Matías, J.; Serrano, E.; Gómez-Ortiz, A.; González-García, M.; Rico, I. Geomatics techniques applied to glaciers, rock glaciers, and ice patches in Spain (1991-2012). Geogr. Ann. Ser. A Phys. Geogr. 2014, 96, 307-321. [CrossRef]

35. Faillettaz, J.; Funk, M.; Vagliasindi, M. Time forecast of a break-off event from a hanging glacier. Cryosphere 2016, 10, 1191-1200. [CrossRef]

36. Margreth, S.; Faillettaz, J.; Funk, M.; Vagliasindi, M.; Diotri, F.; Broccolato, M. Safety concept for hazards caused by ice avalanches from the Whymper hanging glacier in the Mont Blanc Massif. Cold Reg. Sci. Technol. 2011, 69, 194-201. [CrossRef]

37. Giordan, D.; Dematteis, N.; Allasia, P.; Motta, E. Classification and kinematics of the Planpincieux Glacier break-offs using photographic time-lapse analysis. J. Glaciol. 2020, 66, 188-202. [CrossRef]

38. Dematteis, N.; Luzi, G.; Giordan, D.; Zucca, F.; Allasia, P. Monitoring Alpine glacier surface deformations with GB-SAR. Remote Sens. Lett. 2017, 8, 947-956. [CrossRef]

39. Dematteis, N.; Giordan, D.; Zucca, F.; Luzi, G.; Allasia, P. 4D surface kinematics monitoring through terrestrial radar interferometry and image cross-correlation coupling. ISPRS J. Photogramm. Remote Sens. 2018, 142, 38-50. [CrossRef]

40. Giordan, D.; Allasia, P.; Dematteis, N.; Dell'Anese, F.; Vagliasindi, M.; Motta, E. A low-cost optical remote sensing application for glacier deformation monitoring in an alpine environment. Sensors 2016, 16, 1750. [CrossRef]

41. Giordan, D.; Dematteis, N.; Troilo, F.; Segor, V.; Godone, D. Close-Range Sensing of Alpine Glaciers. In Glaciers and Polar Environment; IntechOpen: London, UK, 2020; ISBN 978-1-83962-593-0.

42. World Glacier Monitoring Service (WGMS). World Glacier Inventory: Status 1988; Haeberli, W., Bösch, H., Scherler, K., Østrem, G.W., Eds.; IAHS(ICSI)/UNEP/UNESCO, World Glacier Monitoring Service: Zurich, Switzerland, 1989.

43. Raup, B.; Racoviteanu, A.; Khalsa, S.J.S.; Helm, C.; Armstrong, R.; Arnaud, Y. The GLIMS geospatial glacier database: A new tool for studying glacier change. Glob. Planet. Chang. 2007, 56, 101-110. [CrossRef]

44. Pralong, A.; Funk, M. On the instability of avalanching glaciers. J. Glaciol. 2006, 52, 31-48. [CrossRef]

45. Faillettaz, J.; Funk, M.; Vincent, C. Avalanching glacier instabilities: Review on processes and early warning perspectives. Rev. Geophys. 2015, 53, 203-224. [CrossRef]

46. GlaRiskAlp. Available online: http:/ / www.glariskalp.eu/ (accessed on 1 February 2021).

47. Strozzi, T. Monitoraggio del ghiacciaio di Planpincieux in Valle d'Aosta (Italia); Istituto di Ricerca per la Protezione Idrogeologica: Gumligen, Switzerland, 2014.

48. Leica TM30 Technical Data. Available online: https://w3.leica-geosystems.com/downloads123/zz/tps/tm30/brochuresdatasheet/tm30_technical_data_en.pdf (accessed on 1 February 2021).

49. Faillettaz, J.; Pralong, A.; Funk, M.; Deichmann, N. Evidence of log-periodic oscillations and increasing icequake activity during the breaking-off of large ice masses. J. Glaciol. 2008, 54, 725-737. [CrossRef]

50. Lucianaz, C.; Rorato, O.; Allegretti, M.; Mamino, M.; Roggero, M.; Diotri, F. Low cost DGPS wireless network. In Proceedings of the 2011 IEEE-APS Topical Conference on Antennas and Propagation in Wireless Communications, Torino, Italy, 12-16 September 2011; pp. 792-795.

51. Dematteis, N.; Giordan, D. Comparison of digital image correlation methods and the impact of noise in geoscience applications. Remote Sens. 2021, 13, 327. [CrossRef]

52. Travelletti, J.; Delacourt, C.; Allemand, P.; Malet, J.P.; Schmittbuhl, J.; Toussaint, R.; Bastard, M. Correlation of multi-temporal ground-based optical images for landslide monitoring: Application, potential and limitations. ISPRS J. Photogramm. Remote Sens. 2012, 70, 39-55. [CrossRef]

53. Pralong, A.; Birrer, C.; Stabel, W.A.; Funk, M. On the predictability of ice avalanches. Nonlinear Process. Geophys. 2005, $12,849-861$. [CrossRef] 
54. Sevestre, H. Extreme Summer Impacts Ice Shelves and Glaciers. Available online: https://public.wmo.int/en/media/news/ extreme-summer-impacts-ice-shelves-and-glaciers (accessed on 1 October 2020).

55. Schweizer, J.; Margreth, S. Evaluation of Hazard Caused by Ice Avalanches from the Planpincieux Glacier, Val Ferret, Courmayeur, Italy; Update 2020; Part 1: Summer Scenarios; European Geosciences Union: Davos, Switzerland, 2020; Available online: https:/ / meetingorganizer.copernicus.org/EGU2020/EGU2020-9717.html?pdf (accessed on 10 June 2021).

56. Cloude, S.R.; Pottier, E. An entropy based classification scheme for land applications of polarimetric SAR. IEEE Trans. Geosci. Remote Sens. 1997, 35, 68-78. [CrossRef]

57. Baffelli, S.; Frey, O.; Hajnsek, I. Polarimetric analysis of natural terrain observed with a ku-band terrestrial radar. IEEE J. Sel. Top. Appl. Earth Obs. Remote Sens. 2019, 12, 5268-5288. [CrossRef]

58. Notti, D.; Cina, A.; Manzino, A.; Colombo, A.; Bendea, I.H.; Mollo, P.; Giordan, D. Low-cost GNSS solution for continuous monitoring of slope instabilities applied to Madonna del Sasso Sanctuary (NW Italy). Sensors 2020, 20, 289. [CrossRef]

59. Lenzano, M.G.; Lannutti, E.; Toth, C.; Rivera, A.; Lenzano, L. Detecting glacier surface motion by optical flow. Photogramm. Eng. Remote Sens. 2018, 84, 33-42. [CrossRef] 